Article

\title{
The WIR at 30: Contributions to National and Global Investment Policymaking
}

\author{
Karl P. Sauvant \\ 1 Columbia Center on Sustainable Investment, USA
}

Keywords: international investment law, world investment report, foreign direct investment, fdi policy, government-mne interaction, development, multinational enterprises

10.46697/001c.18052

\section{AIB Insights}

\begin{abstract}
UNCTAD's World Investment Report (WIR) focusses on development-oriented questions related to the interaction between multinational enterprises (MNEs) and governments. It does that with a view toward developing policy recommendations to maximize the positive impact of foreign direct investment and MNE activities on host countries and minimize any negative impacts. This article examines the reason for this focus and approach, as well as a number of related issues, and evaluates how successful UNCTAD has been in pursuing it.
\end{abstract}

The $30^{\text {th }}$ anniversary of the World Investment Report $(W I R)$ provides a unique opportunity to evaluate the policy impact of the WIR. ${ }^{1}$ In my evaluation, I first discuss why the WIR has always paid special attention to policymaking and some of the considerations relevant in this context, and then continue with an evaluation of its policy impact. ${ }^{2}$ While I had the privilege of creating the WIR in 1991 and being in charge of it for the first 14 editions (until 2004), I have of course followed the publication carefully since then, first when Anne Miroux was responsible for it and especially since James Zhan assumed the responsibility for the WIR in 2009 and took the publication to new heights.

\section{POLICY ORIENTATION AND RELATED CONSIDERATIONS}

The WIR pays special attention to policy because, as a product of the United Nations - first the United Nations Centre on Transnational Corporations (UNCTC) and since late 1993 the United Nations Conference on Trade and Development (UNCTAD) - it seeks to influence the policies of its member states. Thus, the purpose is not just to seek to analyze and understand issues and problems, but - importantly - to see how to deal with them in terms of appropriate policies. This is in contrast to much of the academic literature which typically focusses on analysis and does not necessarily proceed to developing policy responses based on the analyses made.

To begin with, those responsible for writing each edition have (and had), to the best of my knowledge, complete autonomy in choosing the theme for each volume and developing policy recommendations. This is helped by the fact that, since the WIR's inception, there has been an intergovernmental consensus that, while there can be negative effects associated with FDI and MNE activity, on balance the impact of such investment is positive - the reason for which all countries seek to attract it.

At the same time, the development of policy responses must account for a number of considerations deriving from the fact that the WIR is the publication of an intergovernmental institution with world-wide membership. (These considerations apply of course to anyone developing policy recommendations in the FDI space; but they are particularly salient for a policy-oriented UN publication.) Complexities arise from the fact that the WIR seeks to be relevant for all countries, regardless of whether they are developed or developing countries or economies in transition-they all seek the tangible and intangible assets associated with FDI to advance their development. However, individual countries have different interests and priorities as to what they seek to obtain from FDI and MNE activities. For some, it is the creation of additional productive capacity and the employment associated with it. For others, it is the acquisition of technology and know-how, as well as the stimulation of exports. Again others may prefer greenfield investment over mergers and acquisitions or, at least in certain sectors (like natural resources), non-equity forms. Or (increasingly) they may prefer commercially viable investment that is characterized by best efforts to make a reasonable contribution to the economic, social and environmental development of host countries and that takes place in the context of good governance mechanisms. Such "sustainable FDI" is characterized by direct corporate action that increases the development impact of FDI. Pursuing different objectives means putting different policies in place.

Moreover, countries have vastly different capabilities to implement policies. A given policy recommendation to deal with, say, transfer pricing or restrictive business practices, may be appropriate for developed countries or advanced developing counties, but be meaningless for least developed countries. The same applies, to give another example, to the capacity to provide certain incentives and to monitor any conditions that may be attached to them.

From a broader perspective, furthermore, policy recommendations need to take into account several sets of tensions, from both the perspective of MNEs seeking a favor-

\footnotetext{
1 See Buckley (2020) for a review of the WIR contribution to research and Eden (2020) for proposed topics for future WIRs, both in this issue.

2 See UNCTAD (2019) (and earlier editions) for a documentation of the results and impact of UNCTAD’s FDI work in general.
} 
able investment climate and governments seeking to attract FDI and benefit from it as much as possible, and these tensions play themselves out differently for different countries:

- the global corporate interests of MNEs vs. the national development interests of countries;

- foreign vs. domestic ownership;

- policies to attract FDI vs. policies to maximize its benefits;

- a country's interest as a host country vs. its interests as a home country;

- the constraints of an integrated international production system, a globalizing world economy and international investment law vs. the need for policy space in the interest of national development.

It is against this background that the WIR team needs to identify the focus-theme of a given edition and then analyze the issues involved and develop policy recommendations of help to governments.

Given the WIR's policy orientation, the choice of the theme is important, and it delineates what the publication seeks to do. There are at least four key considerations that guide the selection of a theme: it needs to have a clear policy-oriented development focus, center on the nexus of a crucial relationship between governments and MNEs, be of relatively general interest, and be topical.

First, the development focus (while also taking into account other issues) is particularly important because advancing the development of developing countries is in some parts of the world (containing most of humanity) one of the single greatest challenges they face. It is UNCTAD's mission to assist developing countries in this endeavor by providing concrete and actionable policy options. Thus, while there may be many issues that are important, the choice of a WIR theme needs to meet the litmus test of its development relevance.

Second, this litmus test also includes the need for a clear and important interrelationship between FDI and MNE activities, on the one hand, and countries (so far primarily host countries, but, in principle, also home countries-a possible future WIR theme) and their policies, on the other hand. While this, naturally, requires an understanding of the operations of MNEs (and this is where the expertise of AIB members is important), the WIR's analytical focus is not the MNE and its performance. Rather, the analysis has to concentrate on the impact of MNEs on countries and evidence-based policy options related to their impact.

Moreover, the theme chosen needs to be relatively broad, as otherwise it would be of interest only to a very limited number of policymakers in a limited number of countries if a publication with a narrow focus would come to the attention of policymakers in the first place.

Finally, the theme needs to be current, in that it addresses an important issue that governments are grappling with, to attract the attention of policymakers (especially - but not only - in developing countries) in a highly crowded media market. The WIR is helped in this by the fact that the publication has become the single most important source of FDI and related data; $;^{3}$ media typically cover the WIRs' trends analyses and, in the process, draw attention to the policy issues, the publication's principal ambition. While it is assumed that UN delegates will draw the attention of the appropriate institutions in their national capitals to the $W I R$, a successful effort has been made from the beginning to reach out to media - especially newspapers but also television, radio and social media: WIR 2018 was downloaded 300,000 times in 2018 alone (UNCTAD, $2019 \mathrm{iv),} \mathrm{and} \mathrm{WIR}$ 2020 attracted over 900 media reports in at least 80 countries between June and July 2020 alone. ${ }^{4}$ Coming to the attention of policymakers is simply the precondition for having impact, although, of course, this does not necessarily guarantee that any policy recommendations are considered and accepted.

\section{POLICY IMPACT}

In analyzing and seeking to understand issues and problems and developing policy responses, the staff preparing the WIR had - and has - three advantages. First, the WIR team is interdisciplinary. This is important because its focus is on the interaction between MNEs and countries and their governments, and this interaction involves economic, developmental, legal, and political-economy issues, to mention basic ones.

Second, the WIR team has the self-confidence to ask for feedback from the best scholars in academia, especially AIB members, development economists and international investment law experts, including in the context of expert meetings. John Dunning, Sanjaya Lall, and Peter Muchlins$\mathrm{ki}$, in particular, were very much involved in the discussions of the WIRs. Later the publication benefited from the feedback of Richard Baldwin, Peter Buckley, Lorraine Eden, and Gary Gereffi, as well as many others in academia. This peer interaction helps to ensure that the WIRs are solid pieces of work as far as analysis is concerned.

Third, the WIR is embedded in a broad spectrum of work undertaken by UNCTAD. Its team includes not only researchers, but also staff with practical experience in providing technical assistance to developing countries on investment matters, as well as staff involved in intergovernmental deliberations on investment matters and with stakeholders interested in investment matters, many of them brought together in the World Investment Forums. This ground-level and practical experience and interaction with the real, everyday problems of developing countries (an advantage that most scholars in academia do not have) informs the WIR discussions and thereby supplements the analytical capabilities of the WIR staff; allows it to test the formulation of policy recommendation against the reality in host countries; and, in turn, informs subsequent technical assistance activities provided to host countries - which feeds back into its research and policy-analysis work. These technical assistance, intergovernmental and stakeholder links also allow the team to keep its finger on the pulse of the times, so to speak, by knowing and understanding what governments are concerned with.

Importantly, while this multi-disciplinary and multi-dimensional starting point comes already in play when each WIR's theme is determined and policy options are formulated, the link to technical assistance crucially allows the WIR to influence policies, both at the national and international levels, thereby having evidence-based impact in the real 
world.

Before illustrating this impact in more detail, a broader observation is in order.

When the first WIR was prepared in 1991, the Washington Consensus reigned supreme. It called, among other things, for the liberalization of inward FDI.

The WIR took a more nuanced approach. Above all, while the WIR recognized that the tangible and intangible assets associated with FDI are important for development and hence outlined policies to attract these assets, it also noted: "Developing host countries would be well advised to undertake systematic assessments of the foreign direct investment they receive and where it can make a significant qualitative contribution and explore ways and means to enhance that contribution" (WIR 1991: 89). Moreover, and from the beginning, the publication emphasized that FDI and MNE activities involve more than capital flows: they also involve closely interrelated flows of goods and services (trade), technology and skills, i.e., a bundle of tangible and intangible assets organized by MNEs under their common governance (exercised through equity and non-equity means of control). All this implies a considerably more complex process of policymaking than merely attracting investment.

Accordingly, the credo that guided subsequent WIR policy recommendation became: How to maximize the positive effects of FDI and minimize any negative effects? What do we recommend that governments should do? In adopting this approach, the WIR reset the conceptual paradigm within which FDI policies are designed and implemented and gave an overall direction to otherwise fluid policies - then and now.

Discussing the WIR's specific and exclusive policy impact is more difficult. It is clearest when the WIR made an original proposal that was eventually implemented. Other times, various institutions, governments and others - more or less simultaneously and independently of each other - advance similar policy proposals. There can also be substantial timelags between when proposals are made and policymakers take them up, and it cannot be determined whether, when they do, it is because they were advanced in the WIR. Finally, even if policy proposals do not originate in WIRs, but are adopted by it, they may gain traction. In any event, the publication's wide dissemination, combined with UNCTAD's technical assistance and intergovernmental support activities, means that many ideas are being brought to the attention of policymakers, especially in developing countries, and potentially put into practice.

Let me illustrate that policy impact with examples for the national and international policy levels.

\section{POLICY IMPACT AT THE NATIONAL LEVEL}

WIR 1991 recognized (p. 85) that "the individual country remains the most important arena for policy-making." This continues to be the case.

More specifically, one way in which the WIR approaches the question of increasing positive impacts of FDI and limiting negative ones is to look at various dimensions of impact. Separate WIRs examined therefore, for example, employment, trade, competition, non-equity forms, global val- ue chains, and the digital economy - and, for each, developed concrete policy options and advice. Through its technical assistance, this advice has reached over 100 developing countries and, in many instances, is later reflected in national policies.

A few examples illustrate the resulting impact:

- The UNCTAD-pioneered Investment Policy Reviews, an adaptation of the national FDI incentive reviews proposed in WIR 1995 (pp. 301-302), have helped to reshape the FDI policy frameworks of (by mid-2020) 48 requesting countries and one sub-region. Of 442 recommendations made in 15 IPRs undertaken in Africa and Latin America, 340 were at least partially implemented (UNCTAD, 2018: 9). According to a 2018 UNCTAD calculation, the 15 IPR countries for which implementation reports were prepared saw, on average, a 206\% increase in FDI flows in the five years after an IPR was completed, compared to the same period before the review (UNCTAD, 2018: 11). More specifically, FDI flows to these countries rose by $29 \%$ between 2016 and 2017, while they dropped globally by $23 \%$; and while FDI flows to Africa declined by $21 \%$ overall during that period, in the 12 African countries included in the study they rose, on average, by $21 \%$ (UNCTAD, 2018: 11-12).

- WIR 1995 (pp. 84-95) highlighted Africa's investment potential, including by highlighting that rates of return to FDI in Africa are comparable to those in other developing regions. There were attractive but untapped opportunities. Subsequently, African countries were among the first to request investment policy reviews.

- A specific area of benefitting from FDI that is of particular importance for many developing countries and especially the least developed among them - concerns the negotiation of large-scale investment contracts between international investors and national governments. These contracts, especially in the natural resources sector, determine the distribution of benefits between international investors and host countries for decades to come. (This may well be a good theme for a future WIR.) WIR 1999 (pp. 178-179) therefore suggested that a facility be established to help developing countries negotiate fair contracts, an idea that eventually led, in 2017, to the establishment of the CONNEX Support Unit by Germany, precisely with the mandate to provide multidisciplinary contract-negotiations assistance to developing countries. For example, the Support Unit helped Liberia in 2029/2020, together with the International Senior Lawyers Project, to renegotiate an advance pricing agreement for an iron-ore project. The renegotiated agreement method for calculating royalties is expected to increase Liberia's revenues by between $14 \%$ and $24 \%$ over the period 2017 to 2026 not an insignificant improvement for this least-developed African country (Shay, Steel, Beran, \& Abimbola, 2020). ${ }^{5}$

- WIR 2001, dealing with linkages between foreign affiliates and domestic firms, was followed up with a large technical assistance project in Brazil, to help

\footnotetext{
5 For further information on the CONNEX support to Liberia, see https://www.connex-unit.org/en/liberia-connex-supports-governmentto-recoup-lost-state-revenue/.
} 
domestic firms become linkage-ready, by acquiring the capacity to produce at levels of quality and costs expected by foreign affiliates.

- The WIR has paid considerable attention to sustainable development since at least 2012. A number of countries have implemented new investment policies based on the "Investment Policy Framework for Sustainable Development" in WIR 2012 and the action plan for investing in the SDGs laid out in WIR 2014. For instance, based on UNCTAD's guidance, Costa Rica has explicitly integrated the SDGs into the investment-impact evaluation strategy of CINDE, its investment promotion agency. More broadly, the WIR 2014's estimate that the implementation of the SDGs faces a financing gap of some US\$2.5 trillion has informed the international discussion of this subject since 2014.

- The approach of investment promotion agencies (IPAs) and companies, too, is influenced by UNCTAD's work: based on the framework in WIR 2014's "Investing in the SDGs", the World Economic Forum is undertaking a project in four developing countries to identify sustainable FDI challenges and recommend measures to facilitate investment that supports the SDGs. And the World Association of Investment Promotion Agencies (launched in 1995 by UNCTAD) is applying the WIR 2020's recommendations on how to adapt IPA strategies to the COVID-19 impact to its capacity-building programs. ${ }^{6}$

\section{POLICY IMPACT AT THE INTERNATIONAL LEVEL}

WIR 1991 also recognized (p. 86) that "No single country can effectively regulate the activities of transnational corporations, and the boundaries between national and international issues of governance are becoming increasingly blurred." This was true then, and, if anything, has become more of a challenge today, as firms have further internationalized, while most developing countries have only very limited capacity to regulate MNE activity. In fact, the emergence of an integrated international production system the theme of WIR 1993 - raises numerous policy challenges, some of which were discussed in that and subsequent WIRs, including issues related to corporate nationality, MNE group responsibility and international taxation. Some of these challenges were later pursued as policy initiatives, under the heading of corporate social responsibility and, most recently, the OECD's base-erosion-and-profit-shifting project. The challenge of creating a multilateral investment regime is a continuing one.

Not surprisingly, therefore, the quest for, and the nature of, the international governance of MNEs has been a recurring theme of the $W I R$, resulting in substantial policy recommendations. Currently, this global governance regime consists of over 3,000 international investment agreements (IIAs - a concept introduced by the WIR) containing binding obligations to protect MNEs and their investments and facilitating their operations. The regime is enforced by an effective investor-state dispute-settlement (ISDS) mechanism that ensures that obligations are being met - reflected in the over 1,000 ISDS cases brought so far. Moreover, this regime increasingly sets the parameters for national FDI policymaking.

Policy recommendations have concentrated on two aspects of the regime. The first is to balance the obligations of states with obligations of MNEs, including by recognizing the corporate social responsibilities (CSR) of international investors. The rising recognition of this concept in IIAs owes therefore a debt to the WIR.

The second aspect concerns the challenge to help gear the international investment regime toward supporting the Sustainable Development Goals (SDGs) (which also encompass issues related to CSR and related matters). The WIR 2012's "Investment Policy Framework for Sustainable Development” (which include UNCTAD's “Core Principles for Investment Policymaking”) and the WIR 2015's "Reforming the International Investment Regime: An Action Plan" as well as further proposals contained in WIR 2017 and WIR 2018 provided the blueprint that has become a key reference point for international investment policymaking.

As always, the WIRs' global governance recommendations were widely disseminated, including through its technical assistance activities. Thus, UNCTAD organized workshops between 2012-2019 during which some 500 government officials were trained in key IIA issues - a key mechanism to influence those who negotiate such agreements; some 130 countries benefited from its Core Principles for Investment Policymaking; 80 countries and regional organizations received comments from UNCTAD on, or inputs into, the drafting of regional IIAs; and 75 countries profited from the review of their model bilateral investment treaties (BITs) or other IIAs (WIR 2019: 102).

The policy impact has been considerable, as illustrated by a few examples:

- Both negotiators of the pioneering 2016 MoroccoNigeria BIT met during an UNCTAD-organized IIA training course. Following the WIRs' blueprint, that BIT contains not only a strong CSR article but also a number of other innovative provisions aimed at balancing investors' rights and obligations; it also includes an important refinement of the definition of investment by requiring a contribution to sustainable development.

- The 2016 draft Pan African Investment Code benefited from UNCTAD comments based on WIR 2012 and WIR 2015 recommendations, explicitly stating in its preamble that the Code takes "into account ... the Investment Policy Framework for Sustainable Development of the United Nations Conference on Trade and Development (UNCTAD)". 7

- The African, Caribbean and Pacific Group of States (ACP) and UNCTAD jointly developed in 2017 the Guiding Principles for Investment Policymaking for ACP member states (78 countries), drawing on the WIR 2012 proposals.

- Not only developing countries but developed ones too benefitted from the WIR 2012's work: In 2016, the European Parliament adopted a resolution that " 26 . Urges the Commission to advance the UNCTAD comprehensive Investment Policy Framework for Sustainable Development" and "69. Calls on the EU and its Member States to follow UNCTAD’s comprehensive

6 Communication by Bostjan Skalar, Executive Director-CEO, WAIPA, dated 16 September 2020, on file with the author.

7 https://au.int/en/documents/20161231/pan-african-investment-code-paic. 
Investment Policy Framework for Sustainable Development recommendations with a view to stimulating more responsible, transparent and accountable investments." ${ }^{8}$

- And, globally, the 2016 G20 Guiding Principles for Global Investment Policymaking ${ }^{9}$ drew on UNCTAD's Investment Policy Framework for Sustainable Development (Zhan, 2016). The G20 Guiding Principles are the first international consensus on investment matters reached among a group of developed, developing and transition economies, accounting for over twothirds of global outward FDI.

- The WIRs' recommendations are reflected in numerous IIA reforms, undertaken by over 75 countries. In 2019 alone, $82 \%$ of the investment treaties concluded that year contained at least nine reform features in line with UNCTAD's investment policy guidance (WIR 2020: 115).

Reforming the international investment regime is a difficult undertaking, given entrenched interests. The WIR has a long and impact-full history of promoting the reform of this regime, contributing its share to moving this process forward. By helping to modernize the regime, the WIR has made an important contribution to what many - including in AIB - take for granted, namely that the current policy regime allows firms to expand and operate internationally. As we can see now, the regime cannot be taken for granted, but it needs to be improved.

\section{CONCLUSIONS}

To conclude, the WIR has significantly helped to define the mainstream of national and international policymaking toward FDI and MNE activities. The implication for my colleagues in AIB (and others) is clear: if you want to have an impact on policies governing FDI and MNE activities, you should get involved with the WIR.

\section{ACKNOWLEDGMENTS}

I am grateful to Alexandre Dabbou, Hamed El Kady, Khalil Hamdani, and James Zhan for comments on an earlier version of this text.

\section{ABOUT THE AUTHOR}

Karl P. Sauvant, Ph.D. (ksauva@law.columbia.edu) is Adjunct Professor at Columbia Law School and Resident Senior Fellow at the Columbia Center on Sustainable Investment (CCSI). Until February 2012, he was the Founding Executive Director of the Vale Columbia Center on Sustainable International Investment, the predecessor of CCSI. Until July 2005, he was Director of UNCTAD’s Investment Division. While at the UN, he created, in 1991, the annual World Investment Report, its lead author until 2004. He is an AIB Fellow and EIBA Honorary Fellow. He received his Ph.D. from the University of Pennsylvania in 1975. For his recent publications, see: https://ssrn.com/author=2461782 . 


\section{REFERENCES}

Buckley, P. 2020. International Business Research and the World Investment Report: "Big Questions” and Grand Challenges. AIB Insights, 20(4).

Eden, L. 2020. Wither WIR (Redux)? AIB Insights, 20(3).

Shay, S. E., Steel, I., Beran, G., \& Abimbola, O. 2020. Negotiating a Royalty Pricing Agreement: Lessons from Liberia. OECD Development Matters, June 18, 2020. https://oecd-development-matters.org/2020/0 6/18/negotiating-a-royalty-pricing-agreement-lesson s-from-liberia/.
UNCTAD. 2018. Investment Policy Review Implementation Reports: Lessons Learned. https://un ctad.org/en/PublicationsLibrary/diaepcb2018d3 en.p df.

UNCTAD. 2019. Division on Investment and Enterprise: Results and Impact. Report. https://uncta d.org/en/Pages/DIAE/DIAE\%20Publications\%20-\%20 Bibliographic\%20Index/DIAE-Activity-Reports.aspx.

Zhan, J. 2016. G20 Guiding Principles for Global Investment Policymaking: A Facilitator's Perspective. Think Piece Series, World Economic Forum and International Centre for Trade and Sustainable Development. 